\title{
Assessment of periprosthetic joint infection prevention methods amongst Turkish orthopedic surgeons in total joint replacement: A survey
}

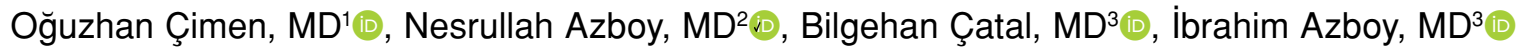 \\ ${ }^{1}$ Department of Orthopedics and Traumatology, Istanbul Medipol Hospital, Istanbul, Turkey \\ ${ }^{2}$ Department of Public Health, Mustafa Kemal University, Faculty of Medicine, Hatay, Turkey \\ ${ }^{3}$ Department of Orthopedics and Traumatology, Medipol University, Faculty of Medicine, Istanbul, Turkey
}

Periprosthetic joint infection (PJI) remains a challenging complication and is a leading reason for failure following total joint arthroplasty (TJA). There is a significant economic burden to the treatment of PJI. ${ }^{[1]}$ In addition to the economic burden, elderly patients with comorbid conditions are at increased risk of postoperative morbidity and mortality when undergoing treatment of PJI. ${ }^{[2]}$

Currently, many different strategies are used to mitigate the risk of PJI after TJA and newer approaches are constantly in development. Several organizations have subsequently recommended evidence-based guidelines for the prevention of PJI and surgical site infections (SSIs). The most notable are the International Consensus Meeting (ICM), ${ }^{[3]}$ World Health Organization (WHO), ${ }^{[4]}$ and the Center for Disease Control and Prevention (CDC) ${ }^{[5]}$ guidelines.

In parallel to new scientific developments, these guidelines sometimes change their recommendations. However, the alignment of orthopedic surgeons with these guidelines may differ due to their experiences

Received: September 18, 2019

Accepted: December 17, 2019

Published online: June 18, 2020

Correspondence: Oğuzhan Çimen, MD. Koşuyolu İstanbul Medipol Hastanesi Ortopedi ve Travmatoloji Bölümü, 34718 Kadıköy, İstanbul, Türkiye.

E-mail: o.cimen@hotmail.com

Citation: Çimen O, Azboy N, Çatal B, Azboy i. Assessment of periprosthetic joint infection prevention methods amongst Turkish orthopedic surgeons in total joint replacement: A survey. Jt Dis Relat Surg 2020;31(2):230-237.

\section{ABSTRACT}

Objectives: This study aims to assess the methods employed by Turkish orthopedic surgeons to prevent periprosthetic joint infection (PJI) in total joint arthroplasty (TJA).

Patients and methods: The data obtained for this study, conducted between January 2019 and February 2019, were gathered by sending out an online survey to Turkish Society of Orthopedics and Traumatology members $(n=2,267)$. A total of 354 orthopedic surgeons responded and completed survey. The survey had 23 questions which include the experience, academic position, hospital where the physician works, monthly arthroplasty numbers, and infection prevention methods employed before, during, and after surgery.

Results: The period for antibiotics prophylaxis showed variability, with about $63 \%$ of surgeons using prophylaxis longer than 24 hours. In terms of academic position, $52.4 \%$ of professors and $52.8 \%$ of associate professors used prophylaxis for the first 24 hours whereas this rate was $31.3 \%$ in operators $(p=0.01)$. Of surgeons, $50.7 \%$ who perform more than 10 arthroplasties per month and $33.6 \%$ of surgeons who perform less than 11 arthroplasties per month used 24-hour antibiotic prophylaxis $(\mathrm{p}=0.006)$. Blood glucose level assessment prior to surgery was performed by the majority of surgeons (94\%). A total of 118 orthopedic surgeons (33.3\%) performed methicillinresistant Staphylococcus aureus (MRSA) decolonization with $54.7 \%$ of associate professors, $59.5 \%$ of professors, and $24.7 \%$ of operators $(\mathrm{p}=0.001)$. Only 60 surgeons $(16.9 \%)$ checked vitamin D levels.

Conclusion: Our study results demonstrated that the majority of orthopedic surgeons in Turkey do not follow the antibiotic prophylaxis recommendations and they use antibiotic prophylaxis for longer periods. Professors and associate professors, and surgeons with higher monthly arthroplasty numbers than surgeons with lower monthly arthroplasty numbers follow the recommended periods more than their counterparts. Most surgeons assess blood glucose levels whereas a small number of surgeons perform MRSA decolonization and check vitamin D levels.

Keywords: Antibiotic prophylaxis, periprosthetic joint infection, prevention, total joint arthroplasty, Turkey. 
and the facilities of the hospitals they work. Therefore, in this study, we aimed to assess the methods employed by Turkish orthopedic surgeons to prevent PJI in TJA.

\section{PATIENTS AND METHODS}

This study was conducted at Medipol University, Faculty of Medicine between January 2019 and February 2019. Data of the study were obtained through an online survey from 354 orthopedic surgeons registered in Turkish Orthopedics and Traumatology Association database $(n=2,267)$ in 2019 and currently performing knee and hip arthroplasty. For this purpose, a draft survey was prepared containing questions about precautions employed by surgeons to reduce PJI risk following primary total knee arthroplasty (TKA) and total hip arthroplasty (THA). Five experienced surgeons operating more than 100 arthroplasties per year were consulted to evaluate the survey. The survey was finalized according to their suggestions. The final survey consisted of 23 questions investigating the demographics of surgeons, their work experience, monthly arthroplasty numbers, and PJI prevention methods employed before, during, and after surgery (Table I). The study protocol was approved by the
Medipol University, Faculty of Medicine Ethics Committee. The study was conducted in accordance with the principles of the Declaration of Helsinki.

\section{Statistical analysis}

All data were entered into the IBM SPSS version 22.0 software (IBM Corp., Armonk, NY, USA). Descriptive statistics and chi-square analysis were used for statistical assessment of data. Significance level was set as $\mathrm{p}<0.05$.

\section{RESULTS}

Seventy-three percent of participants were orthopedic surgeons in this survey. The demographic data of the 354 participating surgeons were listed in Table II.

A total of 257 participants (73\%) started antibiotic prophylaxis one hour before surgery in operating room, whereas $92(26 \%)$ started in the inpatient ward. The antibiotic prophylaxis period showed a great deal of variability. Only 116 orthopedic surgeons $(33 \%)$ used prophylaxis in the first 24 hours. Seventytwo surgeons $(20 \%)$ used prophylaxis for three days and 39 surgeons $(11 \%)$ continued prophylaxis for seven days or longer. Totally, 223 surgeons $(64 \%)$ in total performed prophylaxis longer than 24 hours.

\section{TABLE I}

Survey questions

1. How many years have you been a specialist?

2. Please indicate your academic position.

3. Specify the institution you are working in.

4. How many primary arthroplasty cases do you perform per month?

5. What is your preference for antibiotic prophylaxis?

6. What is your preferred duration of antibiotic prophylaxis?

7. What is your drain preference?

8. What do you use when you need hair removal in patients you plan arthroplasty?

9. What is your approach to patients with diabetes that you plan arthroplasty?

10. What is your approach to alcohol and smoking before surgery?

11. Do you screen patients that you plan elective arthroplasty for urinary infection?

12. Do you perform methicillin-resistant Staphylococcus aureus decolonization before surgery?

13. What is your preference if you are performing methicillin-resistant Staphylococcus aureus decolonization?

14. What are you doing at home for skin cleansing before surgery?

15. When do you operate on arthroplasty cases?

16. What is your routine of using gloves during surgery?

17. What is your preference for the use of iodophor-impregnated drape?

18. Do you use disposable surgical covers?

19. What do you use as a surgical field irrigation solution?

20. What is your preference for using tranexamic acid?

21. Do you use antibiotic cement in cases of primary arthroplasty?

22. What is your preference for vitamin D levels?

23. Would you recommend antibiotic use for patients before dental surgery? 


\begin{tabular}{|c|c|c|}
\hline \multicolumn{3}{|c|}{$\begin{array}{c}\text { TABLE II } \\
\text { Demographic data }\end{array}$} \\
\hline & $\mathrm{n}$ & $\%$ \\
\hline \multicolumn{3}{|l|}{ Workplace } \\
\hline District state hospital & 87 & 24.6 \\
\hline Research and training hospital & 81 & 22.9 \\
\hline Private hospital & 119 & 33.6 \\
\hline University hospital & 67 & 18.9 \\
\hline \multicolumn{3}{|l|}{ Academic position } \\
\hline Orthopedic surgeon & 259 & 73 \\
\hline Associate professor & 53 & 15 \\
\hline Professor & 42 & 12 \\
\hline \multicolumn{3}{|l|}{ Expertise time (year) } \\
\hline $0-5$ & 55 & 15.5 \\
\hline $6-10$ & 112 & 31.6 \\
\hline $11-20$ & 110 & 31.1 \\
\hline $21-30$ & 52 & 14.7 \\
\hline$>30$ & 25 & 7.1 \\
\hline \multicolumn{3}{|c|}{ Number of primary arthroplasties per month } \\
\hline $1-5$ & 153 & 43.2 \\
\hline $6-10$ & 130 & 36.7 \\
\hline $11-20$ & 38 & 10.7 \\
\hline$>20$ & 33 & 9.4 \\
\hline
\end{tabular}

Fifteen surgeons (4\%) used a single-dose preoperative antibiotic prophylaxis.

In terms of academic position, $52 \%$ of professors and $53 \%$ of associate professors used antibiotic prophylaxis for the first 24 hours whereas this rate was $31 \%$ in orthopedic surgeons $(\mathrm{p}=0.001)$ (Table III). Of surgeons, $50.7 \%$ performing more than 10 arthroplasties per month preferred 24-hour antibiotic prophylaxis whereas only $31 \%$ of surgeons performing less than 11 arthroplasties per month preferred this method $(\mathrm{p}=0.006)$ (Table III).
Sixty-one participants $(17 \%)$ performed methicillin-resistant Staphylococcus aureus (MRSA) decolonization in all patients whereas $57(16 \%)$ preferred in selected patients. Fifty-five percent of associate professors, $60 \%$ of professors, and only $25 \%$ of orthopedic surgeons performed MRSA decolonization $(p=0.001)$. Surgeons working in university hospitals preferred MRSA decolonization more compared to surgeons working in research and training hospitals and state hospitals $(48 \%, 36 \%$, and $22 \%$, respectively) ( $\mathrm{p}=0.002)$. The rate of performing MRSA decolonization was $26 \%$ in the participants whose duration of expertise was less than 10 years, whereas it was $40 \%$ in those whose duration of expertise was more than 10 years $(p=0.012)$ (Table IV).

Preoperative blood glucose assessment was performed by the majority (94\%) of surgeons. A total of 102 surgeons (29\%) emphasized that the blood glucose levels should be below $200 \mathrm{mg} / \mathrm{dL}$ whereas 211 surgeons $(60 \%)$ requested blood glucose levels to be below $200 \mathrm{mg} / \mathrm{dL}$ as well as hemoglobin A1c levels to be below 7\%. No statistical significance was found in terms of blood glucose level assessments between academic positions, institution worked or the length of expertise $(\mathrm{p}>0.05)$.

A total of 217 surgeons (61\%) did not make any recommendations to stop alcohol intake and smoking prior to surgery whereas $96(27 \%)$ recommended these one month prior to surgery and $41(12 \%)$ recommended these three months prior to surgery. Orthopedic surgeons were less likely to recommend quitting alcohol intake and smoking compared to associate professors and professors $(\mathrm{p}=0.001)($ Table V).

Totally, 294 participants (83\%) did not check vitamin D levels. Associate professors and professors were significantly more likely to check and regulate vitamin D levels compared to orthopedic surgeons $(\mathrm{p}=0.02)$.

\section{TABLE III}

Comparison of antibiotic prophylaxis duration preference in terms of academic career and number of monthly arthroplasties

\begin{tabular}{|c|c|c|c|c|c|c|}
\hline \multicolumn{2}{|c|}{ First 24 hours after surgery } & \multicolumn{2}{|c|}{ Longer than 24 hours } & \multicolumn{2}{|c|}{ Total } & \multirow[b]{2}{*}{$p$} \\
\hline $\mathrm{n}$ & $\%$ & $\mathrm{n}$ & $\%$ & $\mathrm{n}$ & $\%$ & \\
\hline 81 & 31.3 & 178 & 68.7 & 259 & 100 & \multirow{3}{*}{0.001} \\
\hline 28 & 52.8 & 25 & 47.2 & 53 & 100 & \\
\hline 22 & 52.4 & 20 & 47.6 & 42 & 100 & \\
\hline 95 & 33.6 & 188 & 66.4 & 283 & 100 & \multirow{2}{*}{0.006} \\
\hline 36 & 50.7 & 35 & 49.3 & 71 & 100 & \\
\hline
\end{tabular}




\begin{tabular}{|c|c|c|c|c|c|c|c|}
\hline \multicolumn{8}{|c|}{$\begin{array}{c}\text { TABLE IV } \\
\text { ant Staphylococcus aureus decolonization prefer }\end{array}$} \\
\hline & \multicolumn{2}{|c|}{ Selected patients } & \multicolumn{2}{|c|}{ In all patients } & \multicolumn{2}{|c|}{ In no patient } & \multirow[b]{2}{*}{$p$} \\
\hline & $\mathrm{n}$ & $\%$ & $\mathrm{n}$ & $\%$ & $\mathrm{n}$ & $\%$ & \\
\hline \multicolumn{8}{|l|}{ Academic career } \\
\hline Orthopedic surgeon & 36 & 13.9 & 28 & 10.8 & 195 & 75.3 & \multirow{3}{*}{0.001} \\
\hline Associate professor & 11 & 20.8 & 18 & 34 & 24 & 45.3 & \\
\hline Professor & 10 & 23.8 & 15 & 35.7 & 17 & 40.5 & \\
\hline \multicolumn{8}{|l|}{ Workplace } \\
\hline District State Hospital & 13 & 14.9 & 6 & 6.9 & 68 & 78.2 & \multirow{4}{*}{0.002} \\
\hline Research and Training Hospital & 12 & 14.8 & 17 & 21.0 & 52 & 64.2 & \\
\hline Private Hospital & 22 & 18.5 & 16 & 13.4 & 81 & 68.1 & \\
\hline University Hospital & 10 & 14.9 & 22 & 32.8 & 35 & 52.2 & \\
\hline \multicolumn{8}{|l|}{ Expertise time (year) } \\
\hline $1-10$ years & 25 & 15.0 & 19 & 11.4 & 123 & 73.7 & \multirow{2}{*}{0.012} \\
\hline$>10$ & 32 & 17.1 & 42 & 22.5 & 113 & 60.4 & \\
\hline
\end{tabular}

A total of 121 participants (34\%) did not use tranexamic acid (TXA). Fifty-seven (16\%) used only local, 87 (25\%) used only intravenous (IV) TXA, while $89(25 \%)$ used both IV and local TXA. Sixty percent of orthopedic surgeons used TXA whereas this rate was $83 \%$ in associate professors and $81 \%$ in professors $(\mathrm{p}=0.002)$. While $78 \%$ of participants in research and training hospitals used TXA, this rate was $46 \%$ in those in state hospitals ( $\mathrm{p}=0.001)$ (Table VI).
Fifty-four participants (15\%) recommended a complete body bath using chlorhexidine, 136 (38\%) recommended taking a normal bath, and 74 (21\%) recommended cleaning the surgical field using chlorhexidine or antiseptic soap, while 90 surgeons (25\%) did not have any recommendations.

A total of 172 participants (49\%) recommended antibiotic prophylaxis before dental procedures for

\begin{tabular}{|c|c|c|c|c|c|c|c|}
\hline \multicolumn{8}{|c|}{$\begin{array}{l}\text { TABLE V } \\
\text { aphic data with smoking }\end{array}$} \\
\hline & \multicolumn{2}{|c|}{$\begin{array}{l}\text { I don't recommend } \\
\text { stopping smoking } \\
\text { and alcohol }\end{array}$} & \multicolumn{2}{|c|}{$\begin{array}{l}\text { I recommend stopping } \\
\text { smoking and alcohol } \\
1 \text { month before surgery }\end{array}$} & \multicolumn{2}{|c|}{$\begin{array}{l}\text { I recommend stopping } \\
\text { smoking and alcohol } \\
3 \text { months before surgery }\end{array}$} & \multirow[b]{2}{*}{$p$} \\
\hline & $n$ & $\%$ & $\mathrm{n}$ & $\%$ & $\mathrm{n}$ & $\%$ & \\
\hline \multicolumn{8}{|l|}{ Academic career } \\
\hline Orthopedic surgeon & 169 & 66.5 & 61 & 24.0 & 24 & 9.4 & \multirow{3}{*}{0.001} \\
\hline Associate professor & 24 & 45.3 & 16 & 30.2 & 13 & 24.5 & \\
\hline Professor & 16 & 36.4 & 19 & 43.2 & 9 & 20.5 & \\
\hline \multicolumn{8}{|l|}{ Workplace } \\
\hline District State Hospital & 59 & 70.2 & 16 & 19.0 & 9 & 10.7 & \multirow{4}{*}{0.063} \\
\hline Research and Training Hospital & 41 & 50.6 & 24 & 29.6 & 16 & 19.8 & \\
\hline Private Hospital & 74 & 62.2 & 35 & 29.4 & 10 & 8.4 & \\
\hline University Hospital & 35 & 52.2 & 21 & 31.3 & 11 & 16.4 & \\
\hline \multicolumn{8}{|l|}{ Expertise time (year) } \\
\hline $1-5$ & 39 & 73.6 & 10 & 18.9 & 4 & 7.5 & \multirow{5}{*}{0.152} \\
\hline $6-10$ & 71 & 65.1 & 24 & 22.0 & 14 & 12.8 & \\
\hline $11-20$ & 62 & 56.4 & 33 & 30.0 & 15 & 13.6 & \\
\hline $21-30$ & 25 & 46.3 & 20 & 37.0 & 9 & 16.7 & \\
\hline$>30$ & 12 & 48.0 & 9 & 36.0 & 4 & 16.0 & \\
\hline
\end{tabular}




\begin{tabular}{|c|c|c|c|c|c|c|c|c|c|}
\hline \multicolumn{10}{|c|}{$\begin{array}{l}\text { TABLE VI } \\
\text { Comparison of demographic data with tranexamic acid use }\end{array}$} \\
\hline & \multicolumn{2}{|c|}{ I don't use } & \multicolumn{2}{|c|}{ IV only } & \multicolumn{2}{|c|}{ Local only } & \multicolumn{2}{|c|}{ Both IV and locally } & \multirow[b]{2}{*}{$p$} \\
\hline & $\mathrm{n}$ & $\%$ & $\mathrm{n}$ & $\%$ & $\mathrm{n}$ & $\%$ & $\mathrm{n}$ & $\%$ & \\
\hline \multicolumn{10}{|l|}{ Academic career } \\
\hline Orthopedic surgeon & 104 & 40.2 & 61 & 23.6 & 42 & 16.2 & 52 & 20.1 & \multirow{3}{*}{0.002} \\
\hline Associate professor & 9 & 17.0 & 15 & 28.3 & 9 & 17.0 & 20 & 37.7 & \\
\hline Professor & 8 & 19.0 & 11 & 26.2 & 6 & 14.3 & 17 & 40.5 & \\
\hline \multicolumn{10}{|l|}{ Workplace } \\
\hline District State Hospital & 47 & 54.0 & 18 & 20.7 & 11 & 12.6 & 11 & 12.6 & \multirow{4}{*}{0.001} \\
\hline Research and Training Hospital & 18 & 22.2 & 26 & 32.1 & 17 & 21.0 & 20 & 24.7 & \\
\hline Private Hospital & 38 & 31.9 & 22 & 18.5 & 20 & 16.8 & 39 & 32.8 & \\
\hline University Hospital & 18 & 26.9 & 21 & 31.3 & 9 & 13.4 & 19 & 28.4 & \\
\hline \multicolumn{10}{|l|}{ Expertise time (year) } \\
\hline 1-10 years & 63 & 37.7 & 42 & 25.1 & 28 & 16.8 & 34 & 20.4 & \multirow{2}{*}{0.224} \\
\hline$>10$ & 58 & 31.0 & 45 & 24.1 & 29 & 15.5 & 55 & 29.4 & \\
\hline
\end{tabular}

lifetime, whereas $42(12 \%)$ recommended for one year following surgery, $42(12 \%)$ recommended for three years, and $98(28 \%)$ did not recommend at all.

A total of 208 participants (59\%) ordered urinary screening in all patients prior to surgery whereas 103 $(29 \%)$ ordered in selected patients with $43(12 \%)$ not ordering at all. Totally 276 participants $(78 \%)$ used electric razors whereas $69(20 \%)$ used razorblades, and three $(0.8 \%)$ did not perform epilation. A total of 276 orthopedic surgeons $(78 \%)$ used iodophorimpregnated drape in all patients, whereas $68(19 \%)$ used in selected cases. Totally 313 surgeons $(88 \%)$ used double-layered surgical gloves, with 152 (42.9\%) changing them every hour. A total of 201 (57\%) surgeons used saline solution for irrigation of surgical area following surgery without any antiseptic solutions or antibiotics. Totally 219 participants (62\%) used hemovac drain routinely following surgery with $75(21 \%)$ using them in selected patients with $17(5 \%)$ not using it at all.

\section{DISCUSSION}

The most important result of our study was that the majority of the orthopedic surgeons in Turkey did not follow antibiotic prophylaxis recommendations proposed by guidelines following TJA and they used antibiotics for longer periods. ${ }^{[6]}$

International Consensus Meeting suggests that the antibiotic prophylaxis period should not exceed 24 hours whereas WHO and CDC strongly recommend ending prophylactic antibiotic usage right after closing wound, even in cases where surgical drains are used. There is evidence that antibiotic prophylaxis lasting longer than 24 hours is deemed as unnecessary and might possibly increase bacterial resistance. ${ }^{[7]}$ Furthermore, a recent study reported that a single-dose antibiotic prophylaxis was effective in TJA. ${ }^{[8]}$ Compliance with the recommended 24-hour antibiotic prophylaxis was reported to be $70.2 \%$ in a study in Italy. ${ }^{[9]}$ In our study, 131 orthopedic surgeons (37\%) used 24-hour prophylaxis whereas $223(63 \%)$ used prophylaxis longer than 24 hours. Although the majority of orthopedic surgeons were using antibiotic prophylaxis more than 24 hours, associate professors and professors were in line with current antibiotic prophylaxis recommendations in comparison with operators as well as with surgeons with monthly arthroplasty numbers higher than 10 compared to their counterparts. Future studies may investigate the reasons behind this prolonged antibiotic usage amongst orthopedic surgeons in Turkey.

Staphylococcus aureus (S. aureus) accounts for about $30 \%$ of SSIs. ${ }^{[9]}$ Nasal colonization rate of S. aureus is about $25 \%$, with increasing MRSA rates ${ }^{[10]}$ and SSI risk is known to be higher in nasal MRSA carriers. ${ }^{[1]}$ Although preoperative routine MRSA screening is still debated, decolonization in MRSA carrier patients was shown to decrease SSI risk. ${ }^{[12]}$ World Health Organization strongly recommends the nasal carriers to use $2 \%$ mupirocin. ${ }^{[4]}$ In our study, 236 orthopedic surgeons $(67 \%)$ did not decolonize MRSA whereas 61 (17\%) decolonized MRSA in all patients. The MRSA decolonization rates were significantly higher among 
associate professors and professors compared with operators. We did not question the screening and decolonization methods in this survey. A future study may investigate this issue in detail.

Although skin is a remarkable barrier against microbes, it does host the majority of pathogens which can cause PJI and SSI. Preoperative skin cleansing was shown to decrease bacterial load and SSI rates. ${ }^{[13]}$ According to current evidence, ICM, $\mathrm{WHO}$, and CDC recommend skin cleansing prior to surgery. The cleansing can be performed using antibacterial or antiseptic soaps or antibacterial liquids. Chlorhexidine is probably the most effective agent in such cases due to its effectiveness against most of the pathogens, including MRSA. ${ }^{[14]}$ In this study, 54 orthopedic surgeons $(15 \%)$ recommended a complete body bath using chlorhexidine and $136(38 \%)$ recommended just normal bathing, while the remaining $164(46 \%)$ did not recommend body cleanse at all. This study demonstrates that about half of the orthopedic surgeons in Turkey did not follow the recommendations about preoperative skin cleansing.

About $8-22 \%$ of TJA patients were diagnosed with diabetes, ${ }^{[15]}$ with one-third of those patients with undiagnosed hyperglycemia. ${ }^{[16]}$ Diabetes, particularly uncontrolled diabetes, is an important risk factor for developing PJI. ${ }^{[17]}$ Both WHO and CDC underline the importance of close glycemic control, regardless of diabetes diagnosis before surgery. CDC recommends the fasting blood sugar levels in surgical patients to be below $200 \mathrm{mg} / \mathrm{dL}$. In our study, the majority of the participating surgeons $(94 \%)$ performed glycemic monitoring.

Smoking and alcohol consumption increase PJI risk following arthroplasty. ${ }^{[18]}$ A recent metaanalysis showed that PJI risk following TJA increases by double with alcohol consumption. ${ }^{[19]}$ Similarly, PJI risk after TJA increases by 3.5 times with smoking. ${ }^{[19]}$ It is recommended to stop smoking and alcohol consumption four-eight weeks before surgery. ${ }^{[20,21]}$ In our study, 209 orthopedic surgeons (59\%) did not make any recommendations to stop smoking or alcohol consumption prior to surgery. However, professors and associate professors were more likely to recommend stopping smoking and alcohol consumption. It is remarkable that more than half of the orthopedic surgeons in Turkey did not make any recommendations about quitting smoking and alcohol consumption prior to arthroplasty. It is essential to emphasize the importance of recommending cessation of smoking and alcohol consumption prior to surgery in educational meetings and congress. Preparation of informative brochures targeted to patients might also be beneficial in increasing the awareness about the subject.

Total joint arthroplasty is a major surgery. Blood loss is inevitable and blood transfusion may be required in TJA. Using TXA decreases blood transfusion rates by decreasing intra- and postoperative blood loss. ${ }^{[2]}$ It also decreases the risk of revision for acute and delayed PJI after total knee replacement. ${ }^{[23]}$ In our study, we found that 119 participants (34\%) did not use TXA, with operators with the lowest usage rates. Although TXA is recommended for routine use, it is not routinely used for $62 \%$ in the $\mathrm{UK}^{[24]}$ and $73.1 \%$ in Australia. ${ }^{[25]}$ Compared to other countries, TXA usage is higher among orthopedic surgeons in Turkey.

Immune system enhancing strategies to decrease PJI risk have gained popularity in recent years. ${ }^{[26]}$ Vitamin D supplementation may decrease PJI risk by boosting the immune system. Maier et al.'s ${ }^{[27]}$ study reported vitamin D levels to be lower in patients who develop PJI following arthroplasty compared to others $(p<0.001)$. Zajonz et al.'s ${ }^{[28]}$ prospective study reported that vitamin $\mathrm{D}$ levels were lower in patients who develop acute PJI following TKA and THA, compared to patients who develop chronic PJI $(p=0.002)$. On the other hand, Signori et al. ${ }^{[29]}$ reported that patients who develop PJI have higher vitamin D levels compared to aseptic loosening. In our study, we found out that the majority of the participants did not $(83 \%)$ measure preoperative vitamin D levels. Further studies are required to reach a consensus on this subject.

Symptomatic urinary tract infections are risk factors for PJI and must be treated before TJA. ${ }^{[30]}$ However, asymptomatic bacteriuria (ASB) is frequently seen in TJA patients and should not be considered as a risk factor for PJI. Hence preoperative urine culture and antibiotic treatment are not indicated in patients with ASB. ${ }^{[31]}$ In our study, $59 \%$ of surgeons performed urinary screening routinely whereas $29 \%$ performed it on selected patients, and $12 \%$ did not perform it at all. Routine screening might cause unnecessary treatments and increase costs.

This study has several limitations. Geographical distribution of the orthopedic surgeons participated in the study was not questioned. However, proper distribution of academic positions and institutions can be used to remedy this limitation. Moreover, we did not include the method of choice used for MRSA screening and decolonization. Also, we could not include other risk factors such as history of septic arthritis, immunosuppressive treatment, 
operating room traffic, length of hospital stay, obesity, malnutrition, and chronic diseases since we tried to keep the number of our survey questions limited to evaluate and discuss them properly in limited space for a paper. Future studies are required to assess all other factors in detail.

In conclusion, the present study demonstrated that the majority of orthopedic surgeons in Turkey did not follow antibiotic prophylaxis recommendations proposed by guidelines and they used antibiotics for longer periods. The participants performed blood glucose assessments and urinary screening in higher rates. The majority of the participants did not question the usage of tobacco and alcohol, which was recommended to be questioned by guidelines. Educational documents outlining standard protocols for PJI prevention and discussing those subjects in educational meetings and congresses in detail might be beneficial in raising awareness.

\section{Declaration of conflicting interests}

The authors declared no conflicts of interest with respect to the authorship and/or publication of this article.

\section{Funding}

The authors received no financial support for the research and/or authorship of this article.

\section{REFERENCES}

1. Kurtz SM, Lau E, Watson H, Schmier JK, Parvizi J. Economic burden of periprosthetic joint infection in the United States. J Arthroplasty 2012;27:61-5.

2. Bozic KJ, Lau E, Kurtz S, Ong K, Berry DJ. Patient-related risk factors for postoperative mortality and periprosthetic joint infection in medicare patients undergoing TKA. Clin Orthop Relat Res 2012;470:130-7.

3. Parvizi J, Gehrke T, Chen AF. Proceedings of the International Consensus on Periprosthetic Joint Infection. Bone Joint J 2013;95-B:1450-2.

4. WHO | Global guidelines on the prevention of surgical site infection [Internet]. WHO. Available at: http://www.who. int/gpsc/ssi-prevention-guidelines/en/ [Accessed: Dec 15, 2016].

5. Healthcare Infection Control Practices Advisory Committee (HICPAC). Available at: https://www.cdc.gov/hicpac/pubs. html [Accessed: January 26, 2017].

6. Atik OŞ. Is there something new and interesting in my article? Eklem Hastalik Cerrahisi 2019;30:69.

7. Bratzler DW, Houck PM; Surgical Infection Prevention Guideline Writers Workgroup. Antimicrobial prophylaxis for surgery: an advisory statement from the National Surgical Infection Prevention Project. Am J Surg 2005;189:395-404.

8. Tan TL, Shohat N, Rondon AJ, Foltz C, Goswami K, Ryan SP, et al. Perioperative Antibiotic Prophylaxis in Total Joint Arthroplasty: A Single Dose Is as Effective as Multiple Doses. J Bone Joint Surg [Am] 2019;101:429-37.
9. Agodi A, Auxilia F, Barchitta M, Cristina ML, Mura I, Nobile M, et al. Compliance with guidelines on antibiotic prophylaxis in hip and knee arthroplasty in Italy: results of the GISIO-ISChIA project. Ann Ig 2015;27:520-5.

10. Gorwitz RJ, Kruszon-Moran D, McAllister SK, McQuillan G, McDougal LK, Fosheim GE, et al. Changes in the prevalence of nasal colonization with Staphylococcus aureus in the United States, 2001-2004. J Infect Dis 2008;197:1226-34.

11. Goyal N, Aggarwal V, Parvizi J. Methicillin-resistant Staphylococcus aureus screening in total joint arthroplasty: a worthwhile endeavor. J Knee Surg 2012;25:37-43.

12. Sporer SM, Rogers T, Abella L. Methicillin-Resistant and Methicillin-Sensitive Staphylococcus aureus Screening and Decolonization to Reduce Surgical Site Infection in Elective Total Joint Arthroplasty. J Arthroplasty 2016;31:144-7.

13. Webster J, Osborne S. Preoperative bathing or showering with skin antiseptics to prevent surgical site infection. Cochrane Database Syst Rev 2015:CD004985.

14. Colling K, Statz C, Glover J, Banton K, Beilman G. Preoperative antiseptic shower and bath policy decreases the rate of $S$. aureus and methicillin-resistant $S$. aureus surgical site infections in patients undergoing joint arthroplasty. Surg Infect (Larchmt) 2015;16:124-32.

15. Stryker LS, Abdel MP, Morrey ME, Morrow MM, Kor DJ, Morrey BF. Elevated postoperative blood glucose and preoperative hemoglobin A1C are associated with increased wound complications following total joint arthroplasty. J Bone Joint Surg Am 2013;95:808-14, S1-2.

16. Capozzi JD, Lepkowsky ER, Callari MM, Jordan ET, Koenig JA, Sirounian GH. The Prevalence of Diabetes Mellitus and Routine Hemoglobin A1c Screening in Elective Total Joint Arthroplasty Patients. J Arthroplasty 2017;32:304-8.

17. Marchant MH Jr, Viens NA, Cook C, Vail TP, Bolognesi MP. The impact of glycemic control and diabetes mellitus on perioperative outcomes after total joint arthroplasty. J Bone Joint Surg [Am] 2009;91:1621-9.

18. Singh JA, Houston TK, Ponce BA, Maddox G, Bishop MJ, Richman J, et al. Smoking as a risk factor for short-term outcomes following primary total hip and total knee replacement in veterans. Arthritis Care Res (Hoboken) 2011;63:1365-74.

19. Kong L, Cao J, Zhang Y, Ding W, Shen Y. Risk factors for periprosthetic joint infection following primary total hip or knee arthroplasty: a meta-analysis. Int Wound J 2017;14:529-36.

20. Møller AM, Villebro N, Pedersen T, Tønnesen H. Effect of preoperative smoking intervention on postoperative complications: a randomised clinical trial. Lancet 2002;359:114-7.

21. Tonnesen H, Rosenberg J, Nielsen HJ, Rasmussen V, Hauge $\mathrm{C}$, Pedersen IK, et al. Effect of preoperative abstinence on poor postoperative outcome in alcohol misusers: randomised controlled trial. BMJ 1999;318:1311-6.

22. Sezgin EA, Atik OŞ. Are we scientifically ready to adopt tranexamic acid as a routine in arthroplasty? Eklem Hastalik Cerrahisi 2019;30:338-9.

23. Lacko M, Jarčuška $P$, Schreierova D, Lacková A, Gharaibeh A. Tranexamic acid decreases the risk of revision for acute and delayed periprosthetic joint infection after total knee replacement. Jt Dis Relat Surg 2020;31:8-13.

24. Young B, Moondi P. A questionnaire-based survey investigating the current use of tranexamic acid in traumatic 
haemorrhage and elective hip and knee arthroplasty. JRSM Open 2014;5:2042533313516949.

25. Mayer M, Naylor J, Harris I, Badge H, Adie S, Mills K, Descallar J. Evidence base and practice variation in acute care processes for knee and hip arthroplasty surgeries. PLoS One 2017;12:e0180090.

26. Azboy I, Bedair H, Demirtas A, Ford E Jr, Gahramanov A, Klement MR, et al. General Assembly, Prevention, Risk Mitigation, General Factors: Proceedings of International Consensus on Orthopedic Infections. J Arthroplasty 2019;34:S55-S9.

27. Maier GS, Horas K, Seeger JB, Roth KE, Kurth AA, Maus U. Is there an association between periprosthetic joint infection and low vitamin D levels? Int Orthop 2014;38:1499-504.

28. Zajonz D, Prager F, Edel M, Möbius R, Daikos A, Fakler JK, et al. The significance of the vitamin $\mathrm{D}$ metabolism in the development of periprosthetic infections after THA and TKA: a prospective matched-pair analysis of 240 patients. Clin Interv Aging 2018;13:1429-35.

29. Signori V, Romanò CL, De Vecchi E, Mattina R, Drago L. May osteoarticular infections be influenced by vitamin $\mathrm{D}$ status? An observational study on selected patients. BMC Musculoskelet Disord 2015;16:183.

30. Azboy İ, Yalvaç ES, Azboy N, Şahin İ, Zehir S. Türkiye'de total diz ve kalça artroplastisinde cerrahların tercihleri ve ameliyathane olanakları: Bir anket [Preferences of surgeons in total knee and hip arthroplasty, and operating room facilities in Turkey: a survey]. Eklem Hastalik Cerrahisi 2016;27:34-40.

31. Parvizi J, Koo KH. Should a Urinary Tract Infection Be Treated before a Total Joint Arthroplasty? Hip Pelvis 2019;31:1-3. 